\title{
Gene Therapy: Fighting against the Next Plateau
}

\author{
Claude Bagnis* \\ Département de Thérapie Cellulaire et Génique, Établissement Français du Sang (EFS) Alpes Méditerranée, \\ 149 boulevard Baille, 13392 Marseille CEDEX 5, France
}

The concept of gene therapy really emerged as a theoretical possibility at the end of the sixties. During the eighties, the gene marking protocol conducted by Steve Rosenberg pointed out the feasibility to genetically modify cells prior to reimplantation into a patient without obvious deleterious side effects, and opened a twelve-year long period of gene therapy clinical trials that have shown to be mostly unsuccessful in terms of therapeutical interest. At the end of the nineties, the gene therapy got closer to the reality with the first true cures of X-linked immunodeficient patients by gene transfer but, on the other hand, with the first death of a patient due to the gene transfer procedure. Some naive ideas of the biological mechanisms underlying the diseases approached, technical difficulties that remain to be improved, sometimes a lack of synergy between the various partners ... several reasons can help us to a posteriori understand this twelve-year plateau. And although some trialsopened to inclusion for business or strategical reasonscould have been avoided, ... this period should not surprise us. But we know now that this time is over. In the successful Alain Fisher's clinical trial to treat X-linked immunodeficient patients, the natural in vivo selection of genetically manipulated cells overpassed the technical problems such as the so poorly efficient gene transfer into true hematopoietic stem cells with murine retroviral vectors or the potential silencing of the expression of the transgene, and showed us that gene therapy can work, assuming that we synergistically combine the various partners. Even if the overall design of the vectors, one of the key problems in this field, has not been strictly modified, the gene transfer tools are now accurately produced and characterized according to the pathology approached. New viruses such as the influenza virus or the lentiviruses are being tested in vitro or in animal models, taking into account that a vector can dramatically fail to elicit a biological event and that the universal vector does not, and may never, exist. The relationships between applied research and basic research is getting more constructive. These two natural partners are now realizing that the failure of gene therapy reflects both some intrinsic technical problems related to gene therapy and difficulties for true and applicable concepts to come out from the basic research environment. The biological mechanisms involved in a pathology are not anymore considered as the combination of reversible single events, but as a cascade of synergistic phenomenon that should be carefully reverted to approach a therapeutical benefit considering that in most of the cases the reversion of a single gene should not be enough to elicit a cure. Lessons from the nineties will prompt emerging technologies such as DNA array, genome analysis, proteomics, cellular therapy, and gene therapy to cross talk. In addition, even if they still emphasize an expectation beyond the reality, the messages coming from the Biotech companies involved in this field, the caritative associations, or the news also get closer to the reality of gene therapy and less participate into the confusion that featured this field for the last ten years. Does it mean that gene therapy is entering a fully constructive period? What should we expect in terms of therapeutical benefit for the patients for the next ten years? At least, it seems that we have now the possibility to set up the adequate tools to fight against the next plateau.

\footnotetext{
* E-mail: claude. bagnis@efs. sante.fr

Fax: +33 4 91189598; Tel: +33491189500
} 

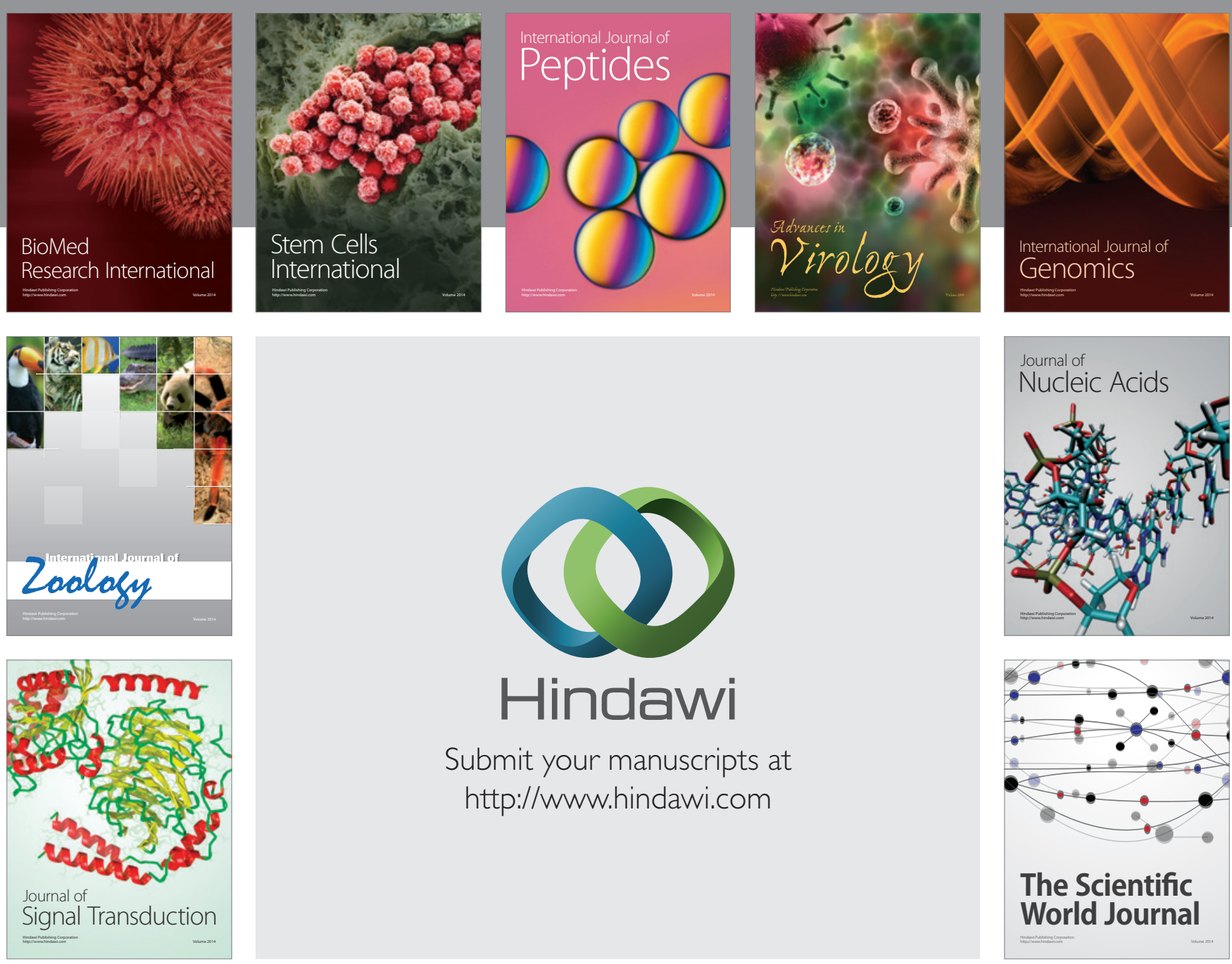

Submit your manuscripts at

http://www.hindawi.com
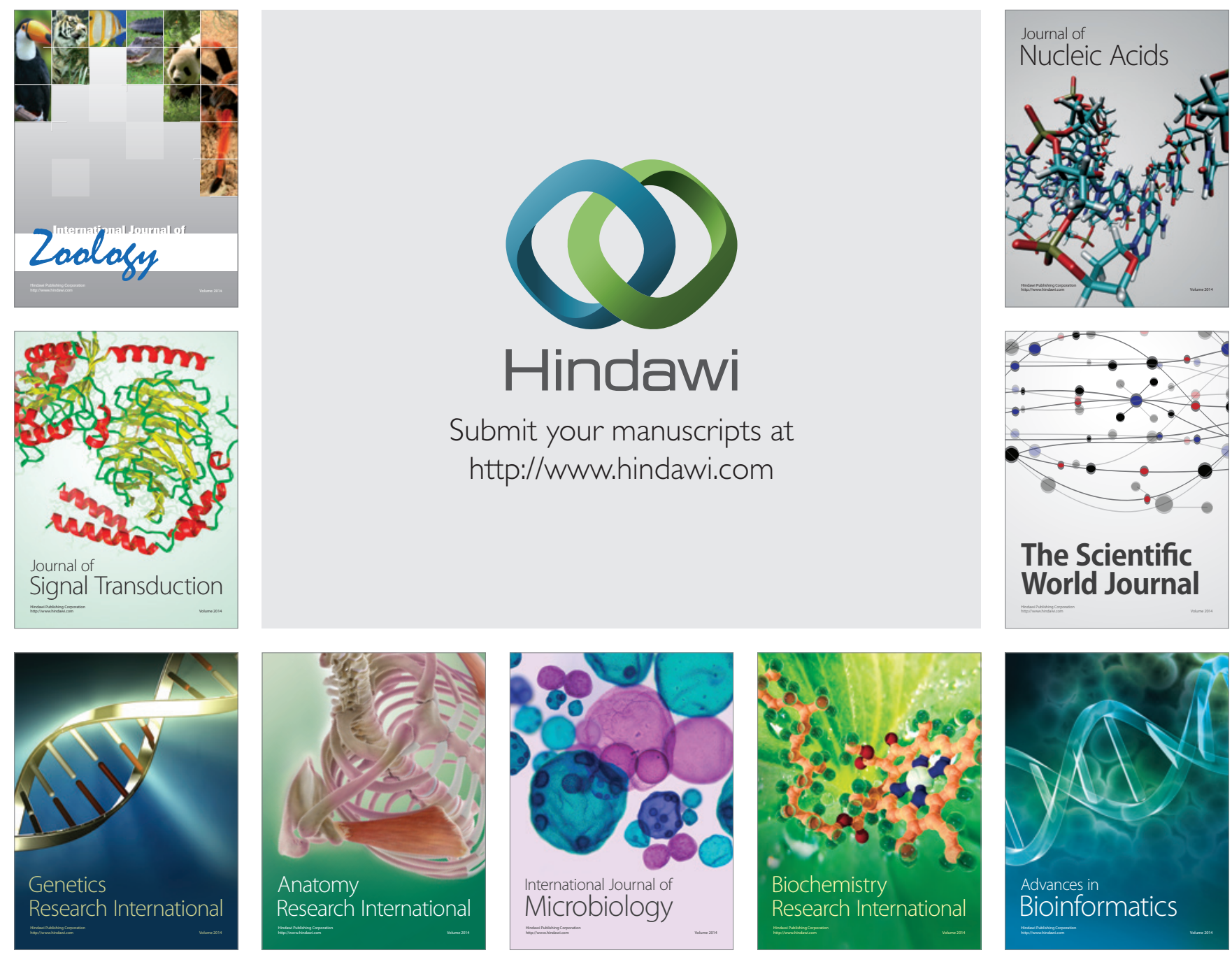

The Scientific World Journal
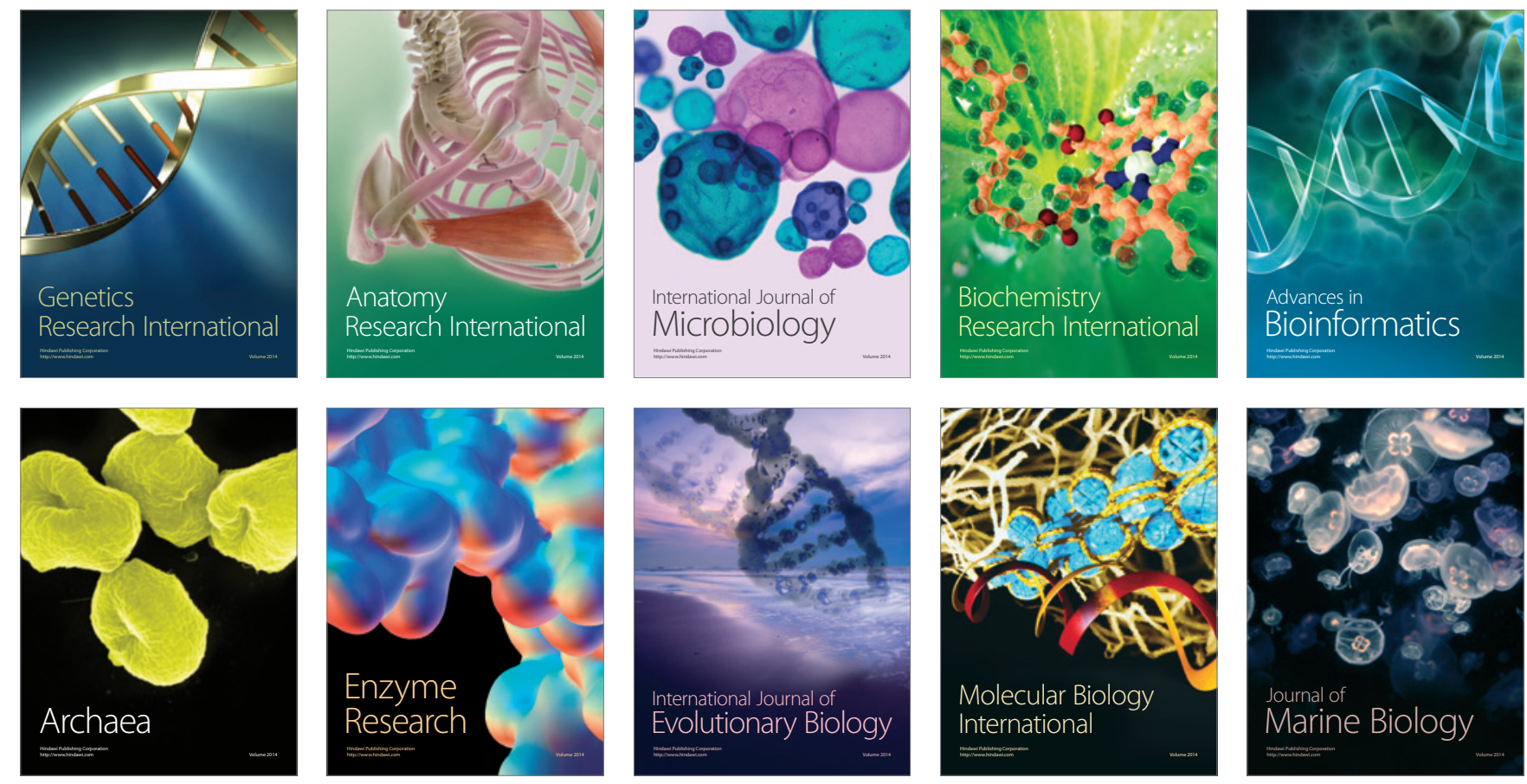